\title{
Range Hood and Make-up Air Supply System to Prevent Dispersion of Cooking-generated Particulate Matter
}

\author{
Hyungkeun Kim, Kyungmo Kang, Taeyeon Kim*
}

Department of Architectural Engineering, Yonsei University, Seoul 03722, Korea

\author{
ABSTRACT
}

Cooking is a major contributor to indoor particulate matter (PM) concentrations. Studies suggest that cooking-generated PM rapidly disperses even when a range hood is in operation, suggesting that range hoods fail to perform sufficiently when used in isolation. However, the performance of range hoods can be improved by a supply of make-up air equivalent to the airflow rate of the range hood. This study evaluates the prevention of the dispersion of cooking-generated PM and the discharge performance when a range hood and ventilation system are integrated. Three operation strategies were established, and the PM concentration was measured to estimate the effect of particle dispersion. An auxiliary supply system (AS) and supply of heat recovery ventilator (HRV) were used for the make-up air supply. The integrated operation of the AS and range hood was effective in preventing PM dispersion during cooking, thereby reducing the maximum PM concentrations by $54.6 \%$ and $75.1 \%$ in the kitchen and living room of the experimental house, respectively. The integrated operation of the HRV and range hood was more effective in discharging dispersed PM after cooking. Based on the results of this study, it is recommended that the integrated application of a range hood and make-up air is applied during and after cooking.

Keywords: Indoor air quality, Cooking, Particulate matter (PM), Ventilation, Range hood, Residential building

\section{OPEN ACCESS}

\section{INTRODUCTION}

Received: July 20, 2020

Revised: October 15, 2020

Accepted: November 22, 2020

${ }^{*}$ Corresponding Author:

tkim@yonsei.ac.kr

Publisher:

Taiwan Association for Aerosol Research

ISSN: $1680-8584$ print

ISSN: 2071-1409 online

cc) Copyright: The Author(s).

This is an open access article distributed under the terms of the Creative Commons Attribution License (CC BY 4.0), which permits unrestricted use, distribution, and reproduction in any medium, provided the original author and source are cited.
In indoor spaces, particulate matter (PM) is generated due to air infiltration or ventilation, building materials, and occupant activities (Spengler et al., 2001). People spend nearly $90 \%$ of their time indoors during the day, primarily in their homes (Klepeis et al., 2001). Many people suffer from a variety of illnesses caused by airborne PM generated in indoor spaces (Kim et al., 2015). In Korea, residential indoor particles are the largest contributor to personal PM exposure (Lim et al., 2012). Particles are generated in indoor spaces due to the movement of polluted outdoor air inside and occupant activities such as smoking, incense burning, cooking, and cleaning (Jones, 1999; Morawska et al., 2003; Liao et al., 2006).

Among these causes of indoor PM, tobacco smoke and cooking are the main particle sources that greatly increase indoor PM concentration (Wanner, 1993; Janssen et al., 1998). Cooking is the most important source of PM among non-smoking households (Wallace, 1996; He et al., 2004; Wan et al., 2011; Macneill et al., 2014). In particular, PM concentrations were found to be up to 30 and 90 times higher than background levels during frying and grilling, respectively (He et al., 2004). Kearney et al. investigated the indoor and outdoor effects of ultrafine particles and showed that indoor-generated particles constitute a large portion and that cooking makes up the greatest percentage (Kearney et al., 2011). Cooking foods at high temperatures can result in rapid PM dispersion (Gao et al., 2015).

Because range hoods are installed separately from mechanical ventilation systems, they are not inter-operated with the existing ventilation system (Kwon et al., 2012). If make-up air is not 
supplied, the performance of the range hood will deteriorate. There are several methods for the supply of make-up air, such as using an auxiliary supply system (AS) or a heat recovery ventilator (HRV; Han et al., 2019). The AS is mainly installed in the kitchen to prevent the dispersion of contaminants and odors from the kitchen to the adjacent living space. The AS is usually installed as a linear diffuser between the kitchen and living room (Kim et al., 2012). Supplying make-up air through a line diffuser has a similar effect to an air curtain, i.e., it can block the transfer of contaminants and heat into the living room. Therefore, supplying make-up air through an AS is the most efficient way to prevent the dispersion of cooking-generated particles. A HRV consists of two ventilation ducts running between the inside and outside of the home. It contains a heat exchanger that uses the moisture of the outgoing exhaust air to heat up the cool air which enters from the outside. It is an effective way to make up air, while also saving energy by preserving indoor temperatures. Nevertheless, the assessment of various make-up air supply methods is still insufficient. Therefore, an evaluation according to the make-up air supply method is required under cooking conditions.

In this study, field measurements were conducted to evaluate the prevention of cookinggenerated PM dispersion via the integrated operation of a range hood and a make-up air supply. Three operation strategies were established and their performances were evaluated to address the problems derived from field measurements.

\section{METHODS}

\subsection{Measurement}

Cooking experiments were conducted in the experimental house of the Air Quality Management Laboratory of Haatz Inc., Pyeongtaek, South Korea. This experimental house was constructed based on the same floor plan as a general apartment house in Korea. The floor area and floor height are $92.57 \mathrm{~m}^{2}$ and $2.3 \mathrm{~m}$, respectively, which are equivalent to a typical mediumsized apartment in Korea. PM was measured in the living room and kitchen. The floor areas of the kitchen and living room were both $47.01 \mathrm{~m}^{2}$. The floor was covered with wooden tiles without carpet. Fig. 1 shows the floor plan of the house and the location of the ventilation diffusers and measurement points.

A multi-speed kitchen exhaust fan was selected for this study (model-K60S, Haatz Inc.), with an exhaust airflow rate of up to $600 \mathrm{CMH}$. The flow rate of the fan was controlled by a separate ventilator (error: 10\%). An aluminum wired grease filter was equipped in the exhaust part of the range hood. An HRV was used for ventilation in the kitchen. The size of the duct was $85 \phi$ and air was supplied with a round-shape diffuser. The supply air (SA) diffusers were located on the ceiling beside the window in the living room. In addition, the AS was installed on the ceiling $2.0 \mathrm{~m}$ from the cooktop (size of the diffuser: $0.69 \times 0.04,276 \mathrm{~cm}^{2}$ ) to assist the range hood. Each ventilation system was controlled in the control center. Because the influence of variables other than the ventilation system needed to be minimized for accurate measurement, the target space was taped to ensure airtightness.

The process of each cooking test was as follows. The broiling method was applied because it has a high PM emission rate and is a widely employed cooking method in Korea. Pork belly, which is a popular cuisine in Korea, was selected as the ingredient for cooking. Broiling uses gas as a fuel in addition to electricity, generating many fine particles (Dennekamp et al., 2001). An electric stove (induction unit) was used to keep the cooktop temperature constant during cooking and prevent PM generation due to combustion by gas fire. A cooking procedure with high heat on the front burner could lower the capture efficiency of the range hood and boost particle dispersion due to a faster plume rise (Rim et al., 2012; Lunden et al., 2015). To evaluate the performance of cooking-generated particle dispersion prevention, the cooking procedure was performed on the front burner.

In the measurement process, cooking was carried out for a total of 15 minutes and was commenced after an initial 3 minutes of waiting time and an additional 2 minutes for preheating the frying pan. Pork belly $(300 \mathrm{~g})$ and cooking oil (soybean oil, $10 \mathrm{~mL}$ ) were added together and heated at temperature level $5\left(153^{\circ}\right)$ for 10 minutes. The pork belly was flipped every 2 minutes to avoid burning. PM measurements were taken for 45 minutes after cooking (Fig. 2). 


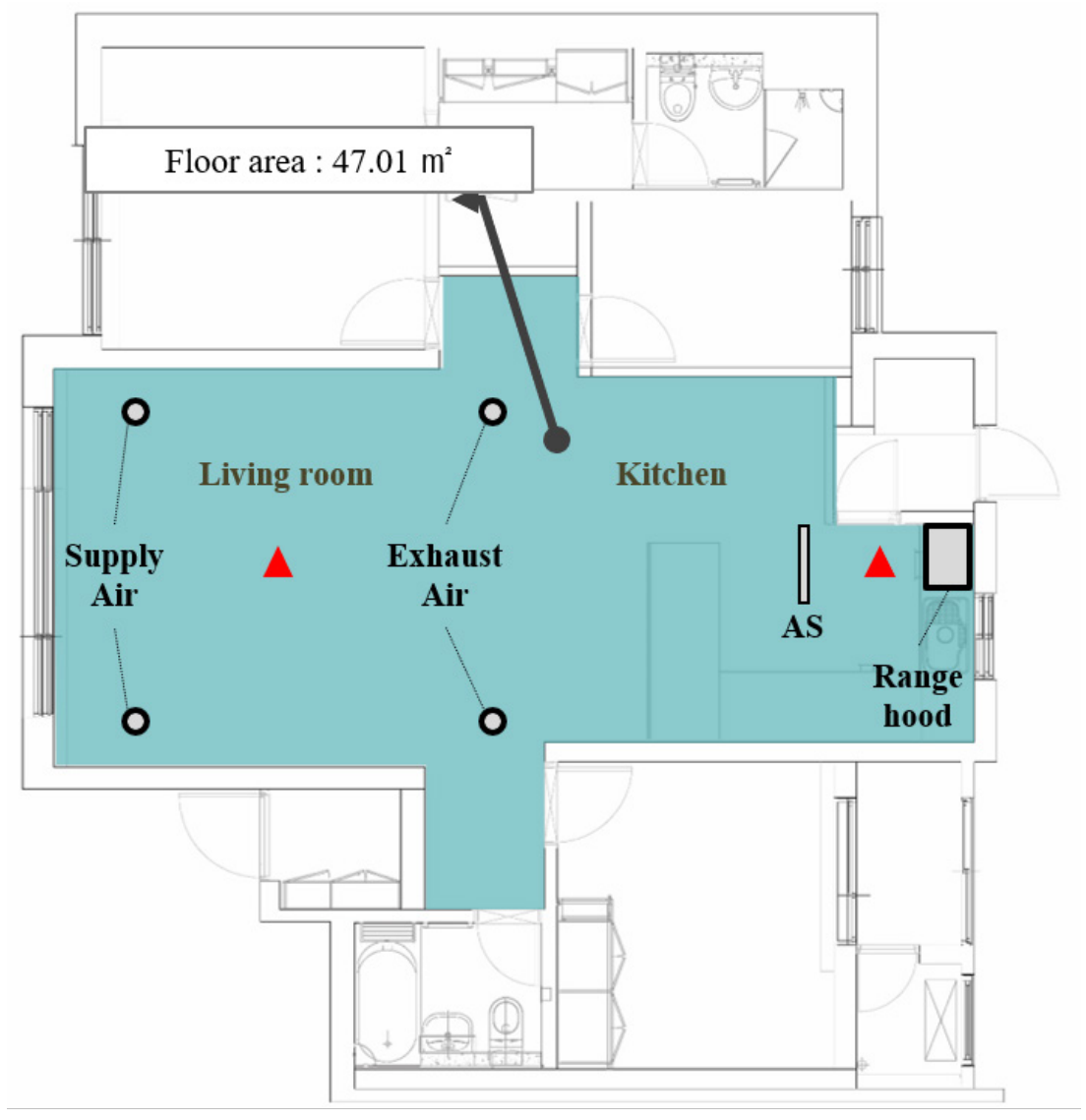

Measurement points

Fig. 1. Floor plan of the experimental house used in this study.

Time [min]

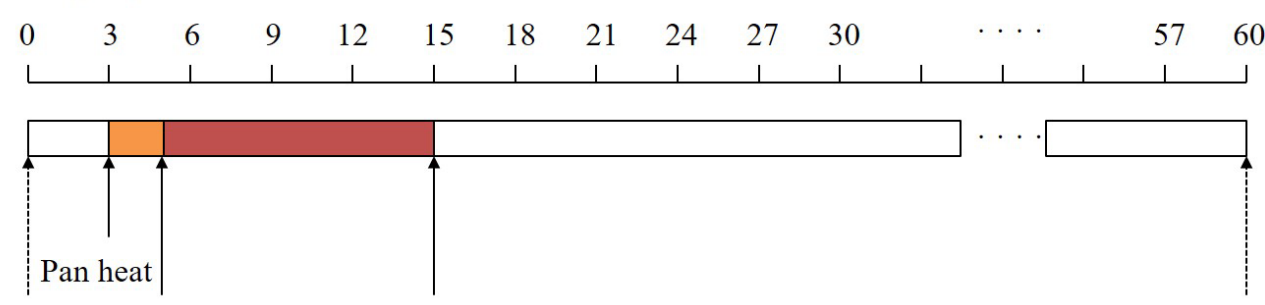

Start Cooking started Cooking completed

Fig. 2. Measurement schedule.

Measurement instruments were located in the kitchen and the living room (Fig. 3). In the kitchen, the measurement instruments were placed in front of the cooktop, $0.5 \mathrm{~m}$ from the stove. In the living room, they were placed in the middle of the room. The sampling tubes of each instrument were fixed with iron poles at a height of $1.5 \mathrm{~m}$. These locations were selected to substitute for the exposure of occupants in the kitchen and living room. Measurement data were collated at 30 second intervals. The mass concentration of $\mathrm{PM}_{2.5}$ (i.e., $\mathrm{PM}$ with an aerodynamic diameter $<2.5 \mu \mathrm{m}$ ) was measured using a TSI DustTrakll (model: 8530, 8532), which is an instrument that applies the light scattering method. The resolution of TSI- 8532 was $\pm 0.1 \%$ and the particle size range was $0.1-2.5 \mu \mathrm{m}$. The light-scattering laser photometer (TSI-8532) was calibrated using gravimetric measurements (MinivolTM TAS) before each experiment was commenced. The Teflon filters were weighed three times using a micro-balance instrument (Cubis II, Sartorius) before and after sampling. The $\mathrm{PM}_{2.5}$ concentration of the cooking event was 


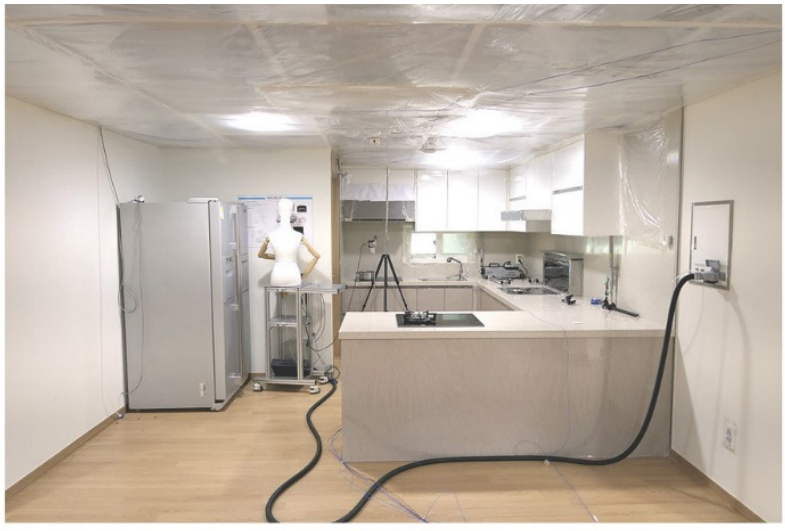

(a) Kitchen

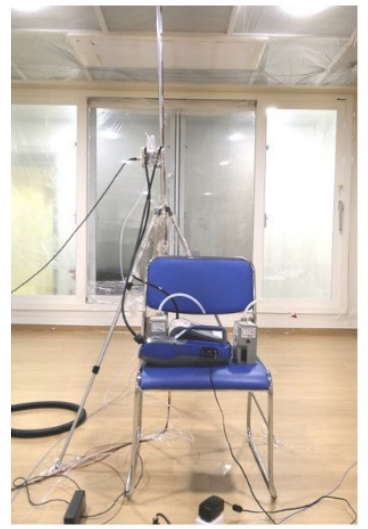

(b) Living room

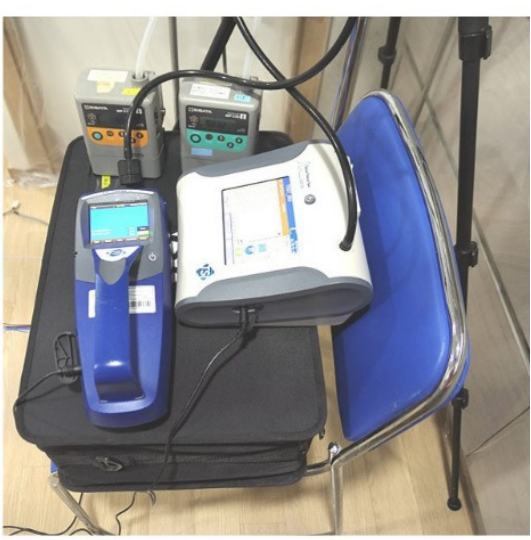

(c) Cooking area

Fig. 3. Measurement instrument at each location.

calibrated by factors of 0.879 against the gravimetric measurement. The concentration of $\mathrm{PM}_{2.5}$ was measured using a TSI OPS-3330. The size resolution of OPS-3330 was $\pm 5 \%$. The particle size range was measured to be in a range of $0.3-2.5 \mu \mathrm{m}$ by OPS-3330. The PM concentration was measured with four channels in the following ranges: $0.3-0.5,0.5-0.7,0.7-1.0$, and $1.0-2.5 \mu \mathrm{m}$. $\mathrm{K}$-type thermocouples were installed to measure temperatures at various points and data were collected with a data logger (SATO SK-L200, Japan).

\subsection{Data Analysis}

Indoor particles can be removed via ventilation through openings, exfiltration of the entire house, and gravitational deposition in the indoor space (Nazaroff and Cass, 1989). Air exchange through ventilation can change rapidly based on the operation of the mechanical equipment including a mechanical ventilation system, cooking exhaust hood, mechanical fan, or the opening of windows and doors. Air exchange by infiltration is influenced by the airtightness of the building, the indoor-outdoor temperature difference, and pressure differences. The PM loss rate in a dwelling is dependent on many factors including the particle size distribution, air temperature, air velocities, and ventilation system (Howard-Reed et al., 2003). To calculate the emission rate for a cooking event, this study referred to the first-order mass balance equation (Chan et al., 2018). In the process of calculating the emission rate, an estimate of the PM loss rate within the decay period is required. We determined the loss rate by fitting the smoothed $\mathrm{PM}_{2.5}$ time series during either the first hour of the decay period or the entire decay period if it was less than $1 \mathrm{~h}$.

The following mass balance equation was used to solve the decay rate of PM due to deposition, ventilation, and infiltration. There was no PM generation during the decay period.

$$
\frac{d C_{\text {in }}}{d t}=P \cdot A \cdot C_{\text {out }}-(A+K) C_{\text {in }}+\frac{E}{V}
$$


here, $C_{\text {in }}$ is the indoor concentration $\left(\mu \mathrm{g} \mathrm{m}^{-3}\right), C_{\text {out }}$ is the outdoor concentration $\left(\mu \mathrm{g} \mathrm{m} \mathrm{m}^{-3}\right), \mathrm{P}$ is the penetration factor, $A$ is the air exchange rate $\left(h^{-1}\right), K$ is the total decay rate of particles $\left(h^{-1}\right), E$ is the emission rate $\left(\mu \mathrm{g} \mathrm{h}^{-1}\right)$, and $\mathrm{V}$ is the volume of the building $\left(\mathrm{m}^{3}\right)$.

The loss rate is the sum of $A$ and $K$. There was no PM emission during the decay period. The loss rate, $L$, was calculated using the following equations:

$$
\begin{aligned}
& C_{i n}(t)-C_{i n_{-} o}=\left(C_{i n}\left(t_{d}\right)-C_{i n_{-} o}\right) \cdot \exp \left(-L\left(t-t_{d}\right)\right), \\
& \ln \left(\frac{C_{i n}(t)-C_{i n_{-} o}}{C_{i n}\left(t_{d}\right)-C_{i n_{-} o}}\right)=-L\left(t-t_{d}\right),
\end{aligned}
$$

where $C_{i n}\left(t_{d}\right)$ is the indoor concentration at the beginning of the decay period $\left(\mu \mathrm{g} \mathrm{m}^{-3}\right)$, and $C_{\text {in_o }}$ is the indoor initial concentration from the outdoor $\mathrm{PM}_{2.5}$ concentration $\left(\mu \mathrm{g} \mathrm{m}^{-3}\right)$.

To calculate the loss rate after fine particles were generated and to then calculate the emission rate $E$, the following equation was used:

$$
\frac{d\left(C_{i n}-C_{i n_{-} o}\right)}{d t}=L\left(C_{i n}-C_{i n_{-} o}\right) .
$$

The relationship between the kitchen and living room was evaluated by the $\mathrm{I} / \mathrm{k}$ ratio of the PM concentration. The $\mathrm{I} / \mathrm{k}$ ratio can be calculated by the concentration of the living room $\left(C_{l}\right)$ over the concentration of the kitchen $\left(C_{k}\right)$ and is used to evaluate the dispersion of cooking-generated particles from the kitchen to the adjacent space. If the $\mathrm{l} / \mathrm{k}$ ratio was $>1$, the particle concentration in the living room was higher than that in the kitchen. If the ratio was $<1$, the particle concentration in the kitchen was higher than that in the living room.

\subsection{Case Studies}

Three case studies were conducted to evaluate the integrated performance of the range hood and the existing ventilation systems. In all cases, the range hood was operated at an airflow rate of $150 \mathrm{CMH}\left(\mathrm{m}^{3} \mathrm{~h}^{-1}\right.$; err. $\left.10 \%\right)$ and continued to operate until the measurements were completed, even after cooking was finished (60 minutes). The details of each case study are shown in Table 1.

In Case 1, measurements were taken only when the range hood was in operation. This case was considered the base model and represents the existing operation method. The laboratory was well sealed and approximately three $\mathrm{ACH}$ infiltrations occurred at $50 \mathrm{~Pa}$. The range hood was operated and make-up air corresponding to the airflow rate of the range hood was supplied as the air infiltration method.

Cases 2 and 3 combined the range hood and ventilation systems. Case 2 involved the simultaneous operation of the range hood and the HRV supply. The HRV is a system in which indoor and outdoor air are exchanged and are then supplied to the room by a heat exchanger. Therefore, in this case, the air supply and exhaust were simultaneously operated. However, when an exhaust is in operation, the PM to be discharged to the range hood may be emitted through an exhaust duct located in the living room, and, therefore, may be dispersed into the living room. To prevent this problem, this study established an integrated operation strategy in which only the make-up air was supplied through a bypass duct of the HRV (i.e., the exhaust air [EA] was

Table 1. Experimental description.

\begin{tabular}{llll}
\hline & Make-up air supply & Airflow rate of make-up air & Airflow rate of range hood \\
\hline Case 1 & - & - & $150 \mathrm{CH}$ \\
Case 2 & Heat Recovery Ventilator (SA) & $150 \mathrm{CMH}$ & $150 \mathrm{CMH}$ \\
Case 3 & Auxiliary Supply system & $150 \mathrm{CMH}$ & $150 \mathrm{CMH}$ \\
Case 4 & Auxiliary Supply system, HRV (SA, EA) & $\mathrm{AS:}$ 150CMH & $150 \mathrm{CMH}$ \\
& & $\mathrm{HRV}(\mathrm{SA}): 150 \mathrm{CMH}$ & \\
& & $\mathrm{HRV}(\mathrm{EA}): 150 \mathrm{CMH}$ & \\
\hline
\end{tabular}


turned off). Two SA diffusers were installed at both ends of the living room close to the terrace. The EA diffuser was installed in the center of the living room and kitchen.

In Case 3, the range hood was operated simultaneously with the AS. Make-up air was supplied to the indoor space through a line diffuser with an airflow rate of $150 \mathrm{CMH}$. The velocity of the supply air was approximately $3.02 \mathrm{~m} \mathrm{~s}^{-1}$. (The area of the diffuser was $276 \mathrm{~cm}^{2}$, but the blade was installed in the middle, the effective area was approximately half the area of the diffuser.) The AS supplied fresh air in a vertical direction (bottom direction from the ceiling) and was installed $2 \mathrm{~m}$ behind the cooktop to minimize the discomfort of occupants who cooked food and prevent the dispersion of PM generated during cooking. The ductwork of the AS was installed separately from the ventilation system of the HRV or range hood. The length of the diffuser was set at $700 \mathrm{~mm}$, similar to the width of the cooktop, to obtain the air curtain effect. Case 4 involved the entire ventilation system. The HRV was operated under constant ventilation conditions and the AS supplied make-up air for the range hood.

All systems were operated for more than 30 minutes before measurement began and the airflow rate was adjusted accordingly. In each case, the range hood and ventilation system continued to operate during the measurement period. A total of three measurements were taken for each case. After comparing the results, three data sets were averaged.

All field measurements were performed for seven days during the summer. During the measurement period, the outdoor temperature averaged $24.76^{\circ} \mathrm{C}$. The PM2.5 concentration of outdoor air was 4-19 $\mu \mathrm{g} \mathrm{m}^{-3}$ during field measurement (average concentration: $10.63 \mu \mathrm{g} \mathrm{m}^{-3}$ ). All outdoor air supplied indoors was supplied after heat exchange with indoor air. In addition, outdoor air was supplied by HRV and AS after it was filtered by a HEPA filter (E12). Therefore, it was assumed that fresh air was supplied to the laboratory.

\section{RESULTS AND DISCUSSION}

\subsection{Loss Rate and Emission Rate}

The $\mathrm{PM}_{2.5}$ concentration in the kitchen and living room without the range hood being in operation was measured to calculate the emission rate of particles generated during cooking. In general, the particle loss rate and the emission rate were measured when the ventilation system was not in operation. However, the experimental house used in this study had high air-tight performance and the volume of cooking-generated particles was very high. In addition, the office was close because the experimental house was located inside the company building (Haatz Inc.). This made it difficult to discharge the high concentrations of fine particles. For this reason, the loss rate and the emission rate were measured while the ventilation system was in operation. The airflow rate was $150 \mathrm{CMH}$, which was supplied to the space through the supply inlets (balcony side) and exhaust outlets (middle of the living room) of the HRV installed in the living room. Indoor $\mathrm{PM}_{2.5}$ concentration was measured in the center of the living room at a height of $1.5 \mathrm{~m}$. The mean $\mathrm{PM}_{2.5}$ concentrations in the kitchen and living room are shown in Fig. 4.

The $\mathrm{PM}_{2.5}$ concentration was almost unchanged until 5 minutes after cooking commenced (i.e., 10 minutes after measurement). Numerous fine particles were generated and the $\mathrm{PM}_{2.5}$ concentration began to increase in the kitchen and living room. Because the range hood was not in operation, fine particles rapidly diffused to the living room via a strong buoyancy effect, increasing the $\mathrm{PM}_{2.5}$ concentration in the living room. Fig. 5 shows the temperature distribution of the kitchen and the living room during cooking. In the kitchen, the higher the height from cookstove, the higher the temperature because of the strong buoyancy effect produced by the heat generated from cooking. In the living room, the temperature of high position was relatively higher than low position. This indicates that the heat generated in the kitchen diffuses into the living room through the ceiling.

The concentration continued to increase for more than 5 minutes after cooking was ceased owing to particle dispersion. The concentration of diffused particles began to decrease linearly approximately 25 minutes after the measurements were taken. Therefore, the loss rate of fine particles was calculated using data obtained after 25 minutes. Fig. 6 shows the loss rate of the decay period of $1.4614 / \mathrm{h}\left(\mathrm{R}^{2}=0.9931\right)$. The emission rate of particles generated during cooking was calculated according to the calculated loss rate and was $47.62 \mathrm{mg} \mathrm{h}^{-1}$. 


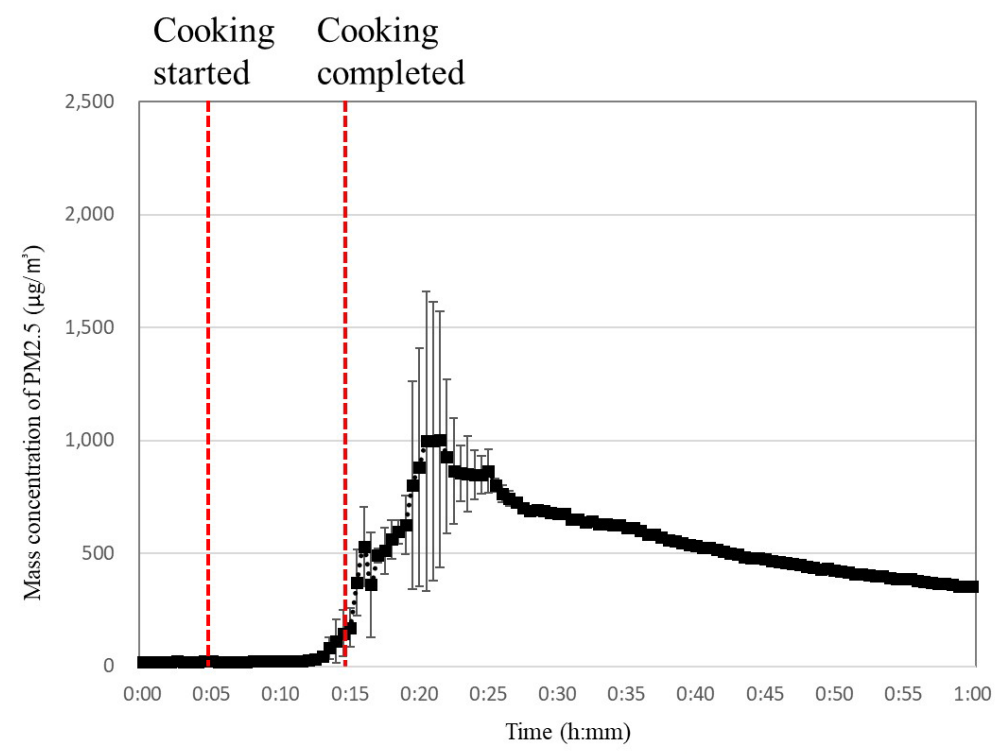

(a) PM2.5 concentration of the kitchen

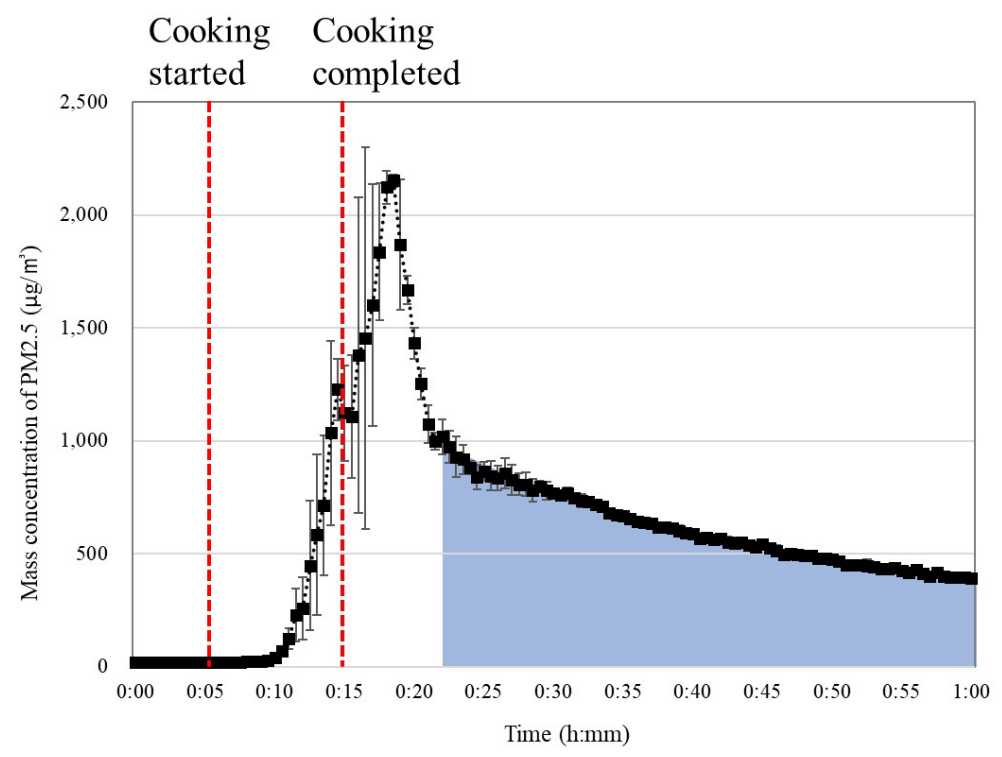

(b) PM2.5 concentration of the living room

Fig. 4. $P M_{2.5}$ concentration with range hood off (PM with an aerodynamic diameter $<2.5 \mu \mathrm{m}$ ) (a) $\mathrm{PM}_{2.5}$ concentration of the kitchen and (b) $\mathrm{PM}_{2.5}$ concentration of the living room. The blue area represents the decay period of the living room.

\section{2 $\mathrm{PM}_{2.5}$ Concentrations of Each Case}

Fig. 7 shows the concentration distribution of $\mathrm{PM}_{2.5}$ in the kitchen and living room during cooking. Firstly, Case 1, the base model, shows a higher concentration than that observed in other cases. If only the range hood was operated, the PM concentration reached a maximum of $300 \mu \mathrm{g} \mathrm{m}^{-3}$ or higher in the kitchen, which is more than 20 times the background concentration of indoor PM $\left(20 \mu \mathrm{g} \mathrm{m}^{-3}\right)$. A minimum concentration of $80 \mu \mathrm{g} \mathrm{m}^{-3}$ was recorded after cooking for 1 hour. In particular, the PM concentration in the living room was very high. Although the PM concentration was higher in the kitchen than in the living room during cooking, after 1 hour the levels in both rooms were similar. This indicates that the PM generated in the kitchen during cooking diffused to the living room and was not rapidly discharged. In addition, this shows that the efficiency of removing fine particles through a range hood is reduced if there is an insufficient supply of make-up air. 


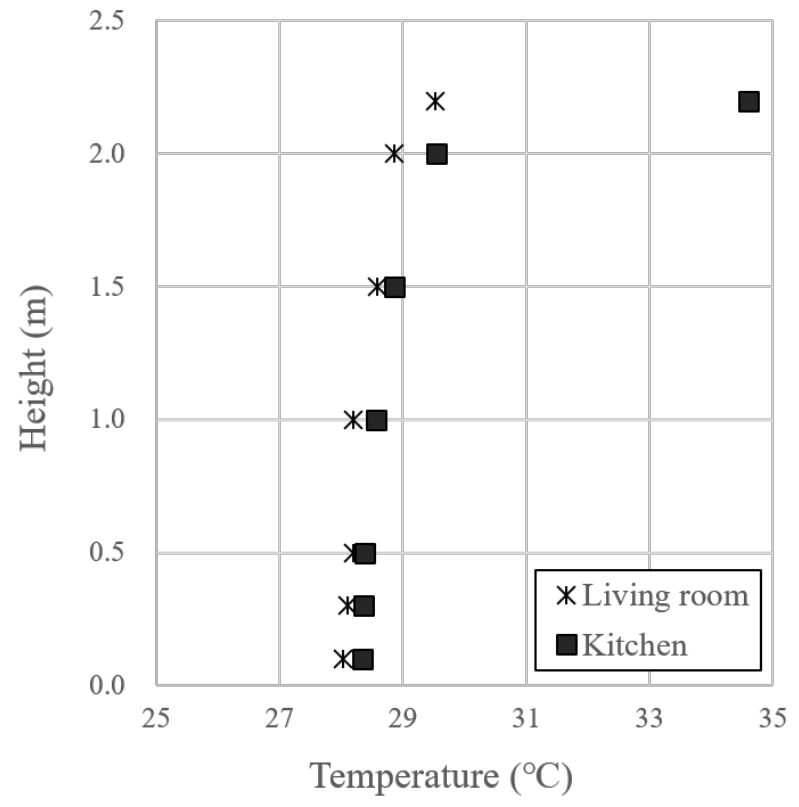

Fig. 5. Temperature distribution of kitchen and living room during cooking.

Time (h)

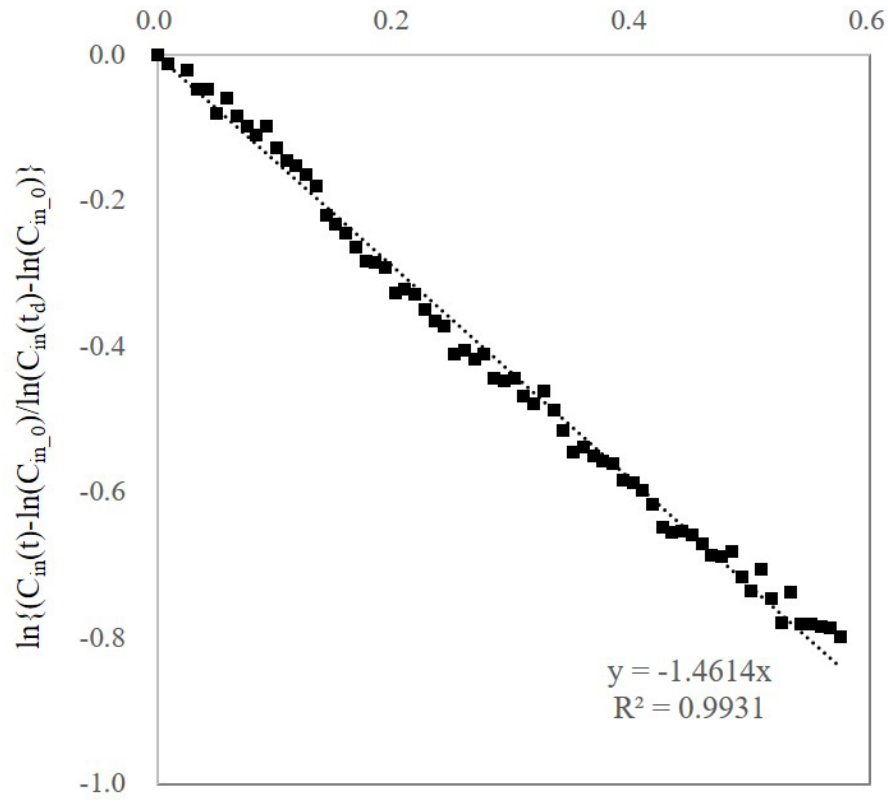

Fig. 6. Particle loss rate and slope of $\ln (\mathrm{Cin} / \mathrm{Cd})$.

In Case 2, the make-up air of the range hood was supplied by the SA diffuser of the HRV. The indoor airflow distribution was expected to naturally diffuse from the living room to the kitchen because the SA diffuser was located toward the living room window. The results showed that the overall $\mathrm{PM}_{2.5}$ concentration was lower than in Case 1 . However, the overall $\mathrm{PM}_{2.5}$ concentration was slightly higher than that in Case 3. In particular, the PM concentration in the kitchen was high. We considered that the airflow was formed gradually in the living room, and therefore, the overall air speed was low. The $\mathrm{PM}_{2.5}$ concentration in the living room increased as fine particles partially diffused from the kitchen during cooking. However, the PM concentration decreased rapidly after cooking was completed. Operating the HRV supply as make-up air was not very effective in preventing PM dispersion during cooking. However, it did effectively discharge dispersed fine particle after cooking. 


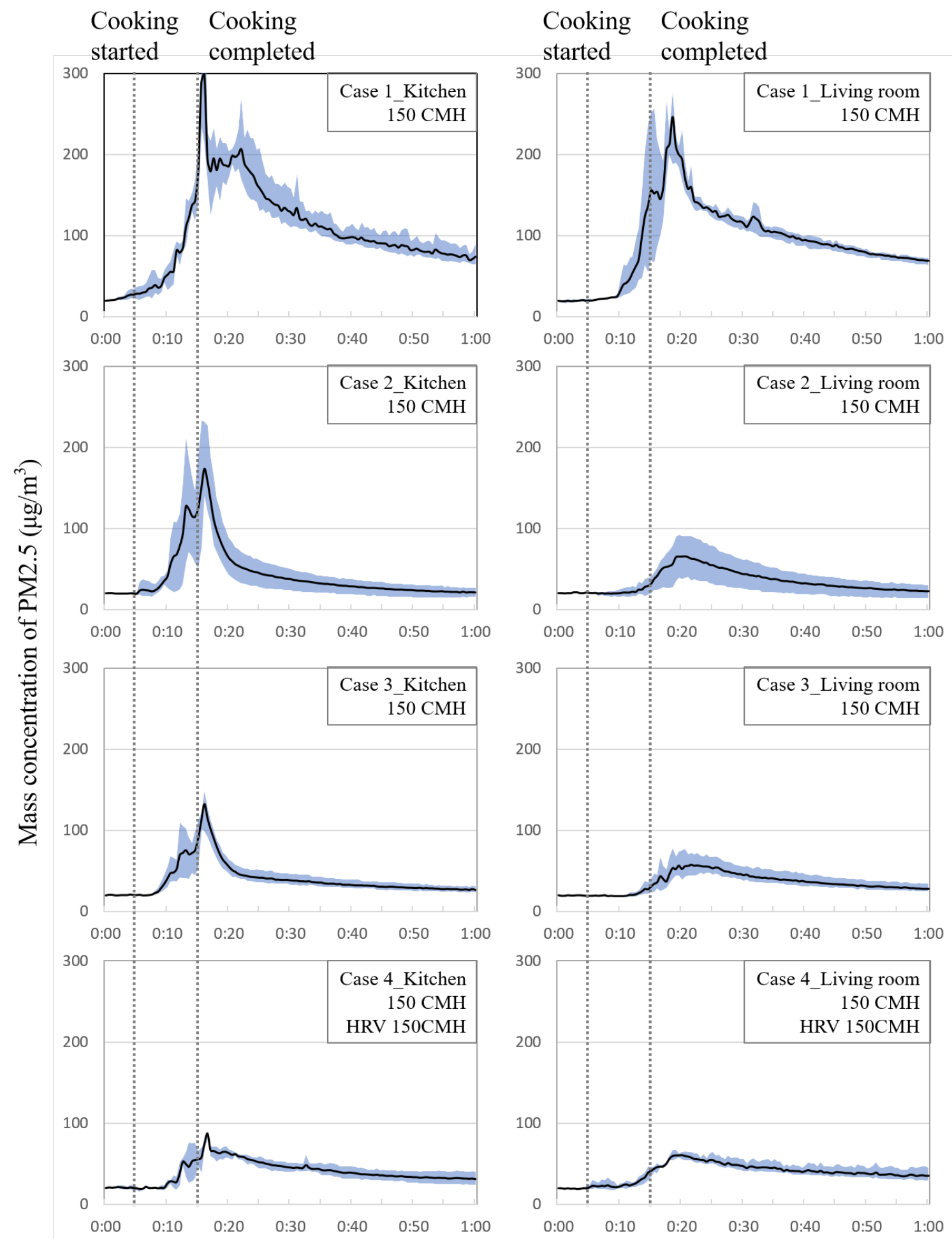

Fig. 7. Mean $\mathrm{PM}_{2.5}$ concentrations and range of each case.

In Case 3, the make-up air of the range hood was supplied through the AS. The diffuser of the AS was installed at the back of the cooktop and effectively prevents particle dispersion. The $\mathrm{PM}_{2.5}$ concentration in the living room was less than half of that in Case 1. In addition, the concentration in the kitchen was generally low, as the PM generated during cooking was quickly discharged through the range hood. The $\mathrm{PM}_{2.5}$ concentration was low in the entire space even after cooking was completed. However, 1 hour after cooking was completed, the concentration in the living room was higher than that in kitchen. Therefore, some of the PM was dispersed to other spaces 


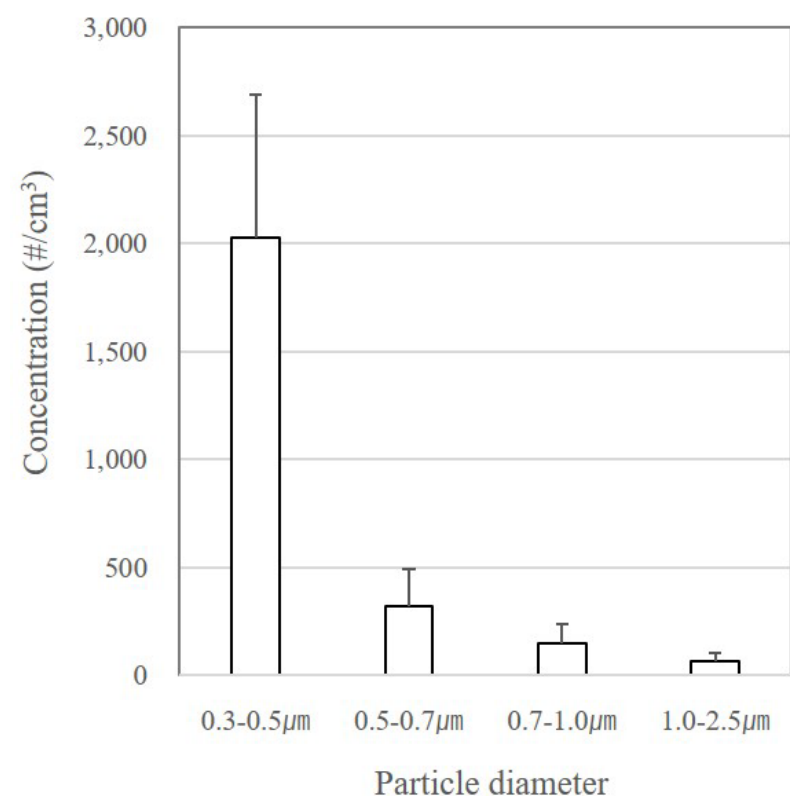

Fig. 8. Average number concentration of base model (Case 1).

and some PM remained in the living room. For the AS, the effect was excellent in preventing PM dispersion; however, the effect may be reduced during the discharge of particles already dispersed to other spaces.

Case 4 had the highest airflow rate; thus, the $\mathrm{PM}_{2.5}$ concentration decreased rapidly. Furthermore, fewer fine particles dispersed into the living room because the living room was supplied with sufficient airflow. However, the concentration observed for Case 4 was twice as high as the other cases. This is considered to be due to the simultaneous discharge of air from the range hood and the EA which scattered the indoor airflow pattern. Even if the volume is small, the make-up air supply can effectively prevent the dispersion of particles generated during cooking. Further, the fine particles can also be discharged rapidly by an effective make-up air plan.

When analyzing the number concentration of fine particles, $80 \%$ of the particles were in the $0.3-0.5 \mu \mathrm{m}$ range, $12 \%$ of particles were in the $0.5-0.7 \mu \mathrm{m}$ range, and $5 \%$ of particles were in the 0.7-1.0 $\mu \mathrm{m}$ range (Fig. 8). As such, particles with a small diameter accounted for the majority of particles generated during cooking. Furthermore, a large $\mathrm{I} / \mathrm{k}$ ratio of the number concentration indicates that several small particles have diffused into the living room.

Fig. 9 shows the $\mathrm{l} / \mathrm{k}$ ratio and standard error over time of the number concentration and the $\mathrm{PM}_{2.5}$ mass concentration. To minimize the confusion caused by data overlapping, the number concentration was indicated by the positive side of the error, while the $\mathrm{PM}_{2.5}$ mass concentration was indicated by the negative side of the error. The $1 / \mathrm{k}$ ratio can be used to determine the level of particle exposure for occupants spending time in the living room. The $\mathrm{l} / \mathrm{k}$ ratio could be affected by the inhomogeneous spatial distribution of PM concentration (Lai and Ho, 2008). If the $l / k$ ratio is $>1$, the fine particles generated during cooking have dispersed, resulting in a higher particle concentration in the living room.

During cooking, the $\mathrm{PM}_{2.5}$ concentration of the kitchen was relatively high as a large number of fine particles were generated during cooking. The $\mathrm{l} / \mathrm{k}$ ratio increased continuously until approximately 25 minutes after cooking was completed, except in Case 1 . This is primarily due to the dispersion of fine particles from the kitchen to the living room, although several fine particles from the kitchen had been discharged through the range hood which reduced the concentration. In Case 1 , the $1 / \mathrm{k}$ ratio was 0.8 or more, even during cooking. This can be inferred from the rapid dispersion of particles generated during cooking, which is equivalent to $>80 \%$ of the concentration measured in the kitchen. Therefore, if only the range hood is operated, residents who do not participate in cooking are at a high risk of exposure to fine particles. Although the I/k ratio was relatively high in Case 4, it is expected that there will be less risk of fine particle exposure in this case as the overall particle concentration was low. Cases 2 and 3 supplied with make-up air 

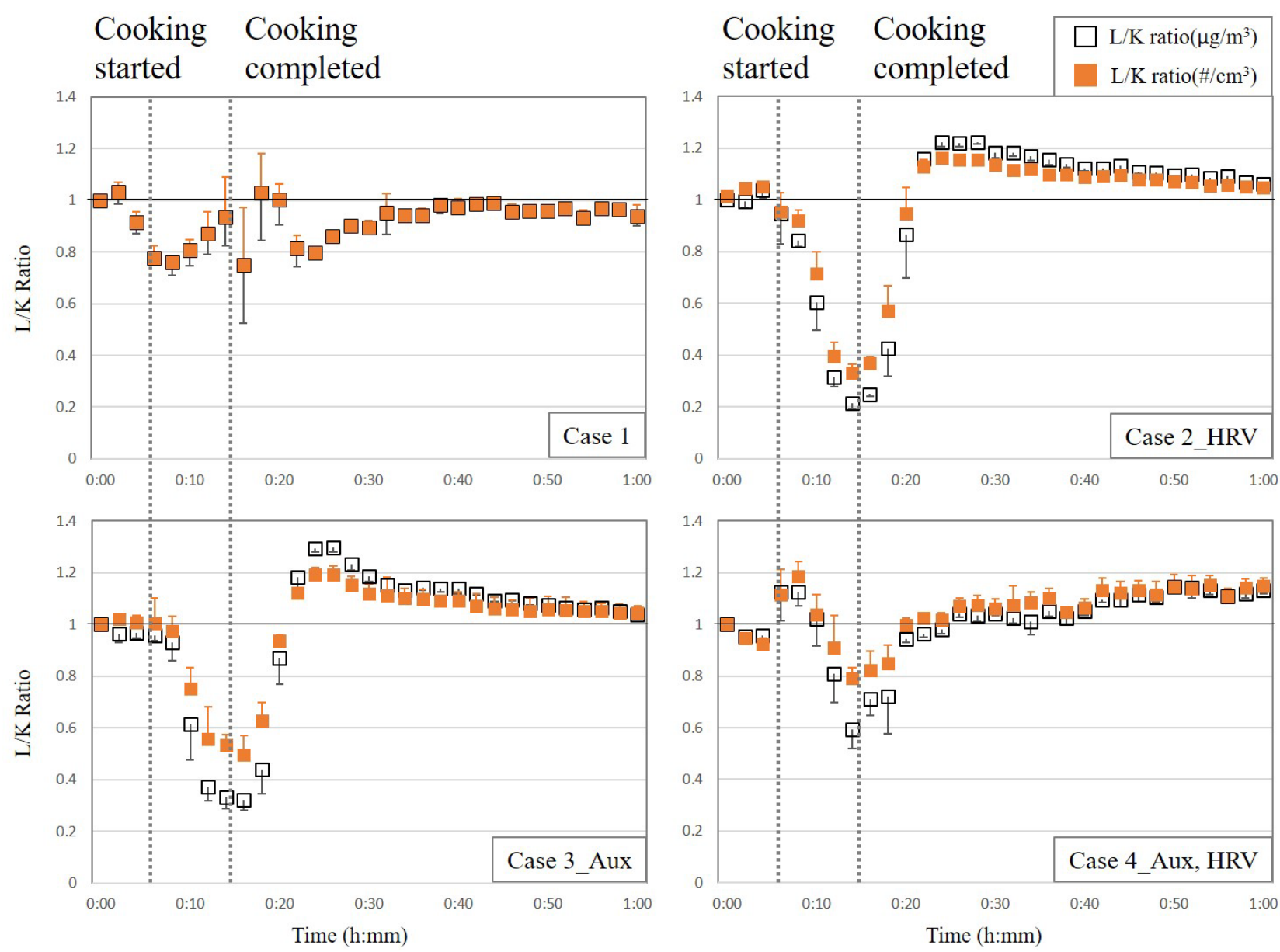

Fig. 9. $1 / \mathrm{k}$ ratio of mass concentration $\left(\mu \mathrm{g} \mathrm{m}^{-3}\right)$ and number concentration $\left(\# \mathrm{~cm}^{-3}\right)$. Error bars indicate $1 \mathrm{standard} \mathrm{error}$.

increased the $1 / \mathrm{k}$ ratio owing to some fine particle dispersion after cooking was completed; however, the I/k ratio continued to decrease from approximately 25 minutes onwards. Both cases appeared to partially disperse fine particles after cooking was completed, however, they were deemed to be effectively discharged. Furthermore, the $\mathrm{l} / \mathrm{k}$ ratio of the number concentration was lower than that of the $\mathrm{PM}_{2.5}$ mass concentration after cooking was completed, which is considered to be due to the discharge of small sized particles through the range hood and the reduction of fine particle dispersion through the make-up air supply. In particular, if the makeup air is supplied through the AS, it is effective in preventing the dispersion of fine particles.

\subsection{Discussion}

The indoor PM concentration was very high during cooking in a Korean residential building. The indoor PM concentration during cooking increased to a maximum of 20 times the background concentration. In addition, the PM quickly dispersed to the living room, even when a range hood was in operation. Operating the range hood is very effective in removing cooking-generated particles. However, when the range hood was operated alone, the airflow rate decreased due to pressure loss and the PM could not be discharged efficiently. To prevent the dispersion of particles generated during cooking, the make-up air needs to be supplied to improve the performance of the range hood.

Table 2 shows the concentration distribution and coefficients of variation (CV) of $\mathrm{PM}_{2.5}$ in the kitchen and living room for various time intervals. The $\mathrm{PM}_{2.5}$ concentration of Case 3 was the lowest in both the living room and kitchen within 30 minutes. However, the PM concentration of Case 2 was lower after 30 minutes. During cooking, the PM concentration was low because the AS prevented the dispersion of PM generated during cooking. Sometime after cooking was completed, the method supplying make-up air from the end of the living room was sufficient for 
Table 2. Average concentration for each time interval.

\begin{tabular}{|c|c|c|c|c|c|c|c|c|}
\hline \multicolumn{3}{|c|}{ Time interval } & $0: 00-15: 00$ & $15: 00-30: 00$ & $30: 00-45: 00$ & $45: 00-60: 00$ & Decay period & Average \\
\hline \multirow[t]{4}{*}{ Case 1} & Kitchen & Average & 54.4 & 177.2 & 104.5 & 80.5 & 109.1 & 103.7 \\
\hline & & CV & 80.4 & 29.1 & 16.3 & 14.9 & 35.1 & 55.8 \\
\hline & Living room & Average & 41.4 & 151.3 & 100.4 & 76.5 & 99.1 & 92.0 \\
\hline & & CV & 107.8 & 27.9 & 12.4 & 8.5 & 24.9 & 55.5 \\
\hline \multirow[t]{4}{*}{ Case 2} & Kitchen & Average & 47.1 & 67.7 & 30.4 & 22.9 & 30.9 & 42.1 \\
\hline & & $\mathrm{CV}$ & 97.5 & 67.6 & 29.5 & 26.4 & 40.9 & 88.1 \\
\hline & Living room & Average & 21.3 & 54.3 & 34.9 & 25.0 & 35.6 & 33.8 \\
\hline & & CV & 23.3 & 37.0 & 35.5 & 32.3 & 47.7 & 53.2 \\
\hline \multirow[t]{4}{*}{ Case 3} & Kitchen & Average & 37.1 & 57.5 & 34.1 & 28.6 & 33.3 & 39.3 \\
\hline & & $\mathrm{CV}$ & 69.9 & 48.1 & 15.5 & 12.8 & 20.5 & 56.2 \\
\hline & Living room & Average & 20.7 & 49.8 & 38.4 & 30.4 & 37.9 & 34.7 \\
\hline & & $C V$ & 18.5 & 25.9 & 20.2 & 17.2 & 28.5 & 38.8 \\
\hline \multirow[t]{4}{*}{ Case 4} & Kitchen & Average & 27.8 & 57.3 & 40.5 & 32.9 & 56.6 & 39.5 \\
\hline & & $\mathrm{CV}$ & 52.5 & 18.9 & 16.5 & 19.2 & 15.7 & 38.2 \\
\hline & Living room & Average & 23.8 & 52.9 & 42.5 & 37.1 & 61.4 & 38.9 \\
\hline & & CV & 28.0 & 13.1 & 15.0 & 18.4 & 12.1 & 32.0 \\
\hline
\end{tabular}

PM discharge. Therefore, operation of the AS during cooking is effective in preventing PM spread. Further, it would be advantageous to operate the HRV and the range hood simultaneously to rapidly discharge fine particles after cooking.

The integrated operation of the AS and range hood is effective in preventing the dispersion of PM during cooking. Using this method, maximum PM concentrations could be reduced by $54.6 \%$ and $75.1 \%$ in the kitchen and living room, respectively. Further, it is necessary to operate the AS and range hood until the PM concentration begins to decrease in the living room. The integrated operation of the HRV and a range hood is effective in discharging the dispersed PM after cooking.

\section{CONCLUSIONS}

Occupant activity is a significant cause of PM generation in residential buildings. In particular, cooking is the largest contributor of fine particles. Therefore, a PM removal strategy is needed to reduce particles generated during cooking. The integrated operation of a range hood and a ventilation system is an effective way to discharge the particles generated during cooking. When the AS and range hood were combined for ventilation, PM dispersion decreased. In this case, the amount of PM dispersed into the living room was the smallest. Integration of the HRV and range hood prevented the dispersion of particles generated during cooking. Furthermore, it showed an excellent performance for the discharge of dispersed PM after cooking. Therefore, it was found that the integration of AS and a range hood during cooking and a HRV and a range hood after cooking were effective in preventing PM dispersion.

\section{ACKNOWLEDGMENTS}

This research was supported by the Basic Science Research Program through the National Research Foundation of Korea (NRF) funded by the Ministry of Science, ICT and Future Planning (NRF-2019R1I1A1A01062777).

This work was supported by a National Research Foundation of Korea (NRF) grant funded by the Korea Government (MSIT, MOE; No. 2019M3E7A1113095).

\section{DISCLAIMER}

The authors declare that they have no known competing financial interests or personal relationships that could have appeared to influence the work reported in this paper. 


\section{REFERENCES}

Cao, C., Gao, J., Wu, L., Ding, X., Zhang, X. (2017). Ventilation improvement for reducing individual exposure to cooking-generated particles in Chinese residential kitchen. Indoor Built Environ. 6 , 226-237. https://doi.org/10.1177/1420326X16673215

Chan, W.R., Logue, J.M., Wu, X., Klepeis, N.E., Fisk, W.J., Noris, F., Singer, B.C. (2018). Quantifying fine particle emission events from time-resolved measurements: Method description and application to 18 California low-income apartments. Indoor Air 28, 89-101. https://doi.org/10. 1111/ina.12425

Delp, W.W., Singer, B.C. (2012). Performance assessment of U.S. residential cooking exhaust hoods. Environ. Sci. Technol. 46, 6167-6173. https://doi.org/10.1021/es3001079

Dennekamp, M., Howarth, S., Dick, C., Cherrie, J., Donaldson, K., Seaton, A. (2001). Ultrafine particles and nitrogen oxides generated by gas and electric cooking. Occup. Environ. Med. 58, 511-516. https://doi.org/10.1136/oem.58.8.511

Dobbin, N.A., Sun, L., Wallace, L., Kulka, R., You, H., Shin, T., Aubin, D., St-Jean, M., Singer, B.C. (2018). The benefit of kitchen exhaust fan use after cooking - An experimental assessment. Build. Environ. 135, 286-296. https://doi.org/10.1016/j.buildenv.2018.02.039

Gao, J., Jian, Y.T., Cao, C.S., Chen, L., Zhang, X. (2015). Indoor emission, dispersion and exposure of total particle-bound polycyclic aromatic hydrocarbons during cooking. Atmos. Environ. 120, 191-199. https://doi.org/10.1016/j.atmosenv.2015.08.030

Han, O., Li, A., Kosonen, R. (2019). Hood performance and capture efficiency of kitchens: A review. Build. Environ. 161, 106221. https://doi.org/10.1016/j.buildenv.2019.106221

He, C., Morawska, L., Hitchins, J., Gilbert, D. (2004). Contribution from indoor sources to particle number and mass concentrations in residential houses. Atmos. Environ. 38, 3405-3415. https://doi.org/10.1016/j.atmosenv.2004.03.027

Howard-Reed, C., Wallace, L., Emmerich, S.J. (2003). Deposition rates of fine and coarse particles in residential buildings: literature review and measurements in an occupied townhouse. In NISTIR-7068, Commerce Department, National Institute of Standards and Technology (NIST). https://doi.org/10.6028/NIST.IR.7068

Janssen, N.A.H., Hoek, G., Brunekreef, B., Harssema, H., Mensink, I., Zuidhof, A. (1998). Personal sampling of particles in adults: relation among personal, indoor, and outdoor air concentrations. Am. J. Epidemiol. 147, 537-547. http://doi.org/10.1093/oxfordjournals.aje.a009485

Jones, A.P. (1999). Indoor air quality and health. Atmos. Environ. 33, 4535-4564. https://doi.org/ 10.1016/S1352-2310(99)00272-1

Kearney, J., Wallace, L., MacNeill, M., Xu, X., Vanryswyk, K., You, H., Kulka, R., Wheeler, A.J. (2011). Residential indoor and outdoor ultrafine particles in Windsor, Ontario. Atmos. Environ. 45, 7583-7593. https://doi.org/10.1016/j.atmosenv.2010.11.002

Kim, K.H., Kabir, E., Kabir, S. (2015). A review on the human health impact of airborne particulate Matter. Environ. Int. 74, 136-143. https://doi.org/10.1016/j.envint.2014.10.005

Kim, T., Park, B.Y., Cheong, C.H. (2012). Ventilation systems to prevent food odour spread in highrise residential buildings. Indoor Built Environ. 21, 304-316. https://doi.org/10.1177/1420326 X11409454

Klepeis, N.E., Nelson, W.C., Ott, W.R., Robinson, J.P., Tsang, A.M., Switzer, P., Behar, J.V., Hern, S.C., Engelmann, W.H. (2001). The National Human Activity Pattern Survey (NHAPS): a resource for assessing exposure to environmental pollutants. J. Exposure Anal. Environ. Epidemiol. 11, 231. https://doi.org/10.1038/sj.jea.7500165

Kwon, Y.I., Jeong, Y.W., Ahn, J. (2012). Study on the performance improvement of roof fan used for local exhaust system installed in apartment. Korean J. Air Cond. Refrig. Eng. 24, 136-141. https://doi.org/10.6110/KJACR.2012.24.2.136

Lai, A.C.K., Ho, Y.W. (2008). Spatial concentration variation of cooking-emitted particles in a residential kitchen. Build. Environ. 43, 871-876. https://doi.org/10.1016/j.buildenv.2007.01.033

Liao, C.M., Chen, S.C., Chen, J.W., Liang, H.M. (2006). Contributions of Chinese-style cooking and incense burning to personal exposure and residential PM concentrations in Taiwan region. Sci. Total Environ. 358, 72-84. https://doi.org/10.1016/j.scitotenv.2005.03.026

Lim, S., Kim, J., Kim, T., Lee, K., Yang, W., Jun, S., Yu, S. (2012). Personal exposures to PM2.5 and 
their relationships with microenvironmental concentrations. Atmos. Environ. 47, 407-412. https://doi.org/10.1016/j.atmosenv.2011.10.043

Lunden, M.M., Delp, W.W., Singer, B.C. (2015). Capture efficiency of cooking-related fine and ultrafine particles by residential exhaust hoods. Indoor Air 25, 45-58. https://doi.org/10.1111/i na.12118

Macneill, M., Kearney, J., Wallace, L., Gibson, M., Héroux, M.E., Kuchta, J., Guernsey, J.R., Wheeler, A.J. (2014). Quantifying the contribution of ambient and indoor-generated fine particles to indoor air in residential environments. Indoor Air 24, 362-375. https://doi.org/10.1111/ina.12 084

Morawska, L., He, C., Hitchins, J., Mengersen, K., Gilbert, D. (2003). Characteristics of particle number and mass concentrations in residential houses in Brisbane, Australia. Atmos. Environ. 37, 4195-4203. https://doi.org/10.1016/S1352-2310(03)00566-1

Nazaroff, W.W., Cass, G.R. (1989). Mathematical Modeling of Indoor Aerosol Dynamics. Environ. Sci. Technol. 23: 157-166. https://doi.org/10.1021/es00179a003

Rim, D., Wallace, L., Nabinger, S., Persily, A. (2012). Reduction of exposure to ultrafine particles by kitchen exhaust hoods: The effects of exhaust flow rates, particle size, and burner position. Sci. Total Environ. 432, 350-356. https://doi.org/10.1016/j.scitotenv.2012.06.015

Singer, B.C., Delp, W.W., Price, P.N., Apte, M.G. (2011). Performance of installed cooking exhaust devices. Indoor Air 22, 224-234. https://doi.org/10.1111/j.1600-0668.2011.00756.x

Sjaastad, A.K., Svendsen, K. (2010). Different types and settings of kitchen canopy hoods and particulate exposure conditions during pan-frying of beefsteak. Indoor Built Environ. 19, 267274. https://doi.org/10.1177/1420326X09347426

Spengler, J.D., Samet, J.M., McCarthy, J.F. (2001). Introduction to the laq Handbook, In Indoor Air Quality Handbook, McGraw Hill Professional, Access Engineering. https://www.mhprofessional. com/9780071414845-usa-indoor-air-quality-handbook

Stratton, J.C., Singer, B.C. (2014). Addressing Kitchen Contaminants for Healthy, Low-Energy Homes, Lawrence Berkeley National Lab. (LBNL), Berkeley, CA (United States). http://aceee.org/files/proceedings/2014/data/papers/1-802.pdf\#page=1

Swierczyna, R.T., Sobiski, P.A. (2003). The effect of makeup air on kitchen hoods. ASHRAE J. 45, K18-K22. https://search.proquest.com/scholarly-journals/effect-makeup-air-on-kitchen-hood s/docview/220461205/se-2?accountid=15179

Wallace, L. (1996). Indoor particles: A review. J. Air Waste Manage. Assoc. 46, 98-126. http://doi.org/10.1080/10473289.1996.10467451

Wan, M.P., Wu, C.L., Sze To, G.N., Chan, T.C., Chao, C.Y.H. (2011). Ultrafine particles, and PM 2.5 generated from cooking in homes. Atmos. Environ. 45, 6141-6148. https://doi.org/10.1016/j. atmosenv.2011.08.036

Wanner, H.U. (1993). Sources of pollutants in indoor air. IARC Sci. Publ. 109, 19-30. https://pubmed.ncbi.nlm.nih.gov/8514347/ 